\title{
A Capability Approach to Real Estate Valuation and Value Enhancement
}

\author{
Janek Ratnatunga ${ }^{a}$ \\ ${ }^{\mathrm{a}}$ Institute of Certified Management Accountants, Australia
}

\begin{abstract}
There are numerous financial metrics available in the academic and commercial world to estimate real estate value. Appraisers often use such metrics when advising on the purchase or sale of real estate at a point in time. The first part of this paper proposes a new metric, based on the capability approach, to make an ex-post single period valuation. Further, appraisers often give advice to their clients on actions to take in order to enhance the value of their real estate. This area of value enhancement has received scant attention in the academic literature. In practice, this advice is often based ad-hoc, anecdotal recommendations. The second part of the paper develops seven real estate strengths that can be targeted and provides an ex-ante approach to building real estate value. The valuation model presented in this paper is a pragmatic approach to enhancing both the values of tangible and intangible capabilities of a property by utilizing Expense Leveraged Value Indexes (ELVI).
\end{abstract}

Keywords: Financial Valuation Metrics, Property Appraisals, Real Estate Capability, Real Estate Value

\section{Introduction}

The valuation of real estate has been high on investors, property owners and scholars' agendas for more than three decades. However, there is still no broad consensus on approach, methodology or even underlying valuation philosophy. Instead, the literature proffers a number of real estate appraisal models. The value usually sought is the property's ex-ante Market Value. To determine this most appraisers use ex-post information 
such as the value-added to the property and the past sales trends in the area. These appraisals of property values are done at a point in time. If done independently of the buyer and seller, that value should be the point at which the two parties would agree and a transaction could take place. A neglected area of valuation is how this value could be enhanced via the targeted expenditure on certain aspects of the property. Whilst appraisers acting for either the seller or the buyer give ad-hoc advice on how value can be enhanced before a seller sells (or after a buyer buys), there is no model that currently exists that enables the appraiser to advise on how the property owner can enhance the capability of the property by targeted expenditure on certain factors. We believe that this paper fills the gap in the literature.

Appraisals are needed because real estate transactions occur very infrequently and thus the market is ill-liquid. Unlike a new consumer product (e.g. a car) or company shares, every property is different from the next, especially in terms of their location. This means that specialist qualified appraisers are needed to advise ex-ante on the value of a property. Often the value is not for a property to be put on the market for sale, but instead used as the basis for mortgage loans, for settling estates and divorces, for tax matters, etc. This article develops an ex-ante appraisal model to enable valuers to pro-actively execute value-enhancing strategies and then provides a hypothetical case example of how it can be implemented.

In real estate, there is both a tangible and an intangible aspect to the asset value. A price paid might not represent that property's tangible value only. Sometimes, special considerations may have been present, such as a special relationship between the buyer and the seller where one party had control or significant influence over the other party. Another example is an owner of a neighboring property who, by combining his own property with the subject property, could obtain economies-of-scale. These intangible values occur when 'the sum is greater than its parts'. In such cases, the price paid for any particular piece is not only its tangible 'value' but rather a value that incorporates intangible factors as well.

In the corporate world, investors and managers are becoming increasingly aware of the value of intangible assets, and how all their assets, both tangible and intangible, combine to produce the capability to lift their firm's economic value. Ratnatunga, Gray, and Balachandran, (2004) reason that, by using specific expense leveraged value indices 
(ELVI), it is possible to calculate the capability economic values for all tangible and intangible assets in a firm.

Similarly, expenditure to build Real Estate Capability (REC) is particularly amenable to such a valuation approach. Such expenses combine and convert tangible and intangible inputs into REC outputs. This paper examines to what extent the Capability Economic Value of Intangible and Tangible Assets approach (Ratnatunga et al., 2004) can be adapted and applied to the valuation of real estate capability values at a point in time, and this approach can also be used in REC enhancing processes.

The paper is set out as follows: First, a review of the extant literature discussing the traditional approaches to real estate valuation is undertaken. The authors then offer a rationale for a new approach to real estate valuation, using the capability valuation approach. The approach is then extended to its use in value enhancement, especially when targeted ex-ante expenditures are required to increase real estate capability values. Next, the paper discusses both established and emerging approaches to valuing capabilities and proposes a comprehensive model of valuing real estate capabilities focusing on seven strengths that enhance real estate values. The authors then provide hypothetical data to test the implementability and validity of the approach. Finally, the article reflects on the learnt value of this process, draws conclusions, and considers the theory-building and practical implications of the approach.

\section{Traditional Approaches to Valuing Real Estate}

There are several types and definitions of value sought by a real estate appraisal. Some of the most common are:

1. Market value: This is the price at which an asset would trade in a competitive Walrasian auction setting. Market value is usually interchangeable with open market value or fair value. International Valuation Standards (IVS) defines market value as the estimated amount for which a property should exchange on the date of valuation between an educated buyer and a reasonably motivated seller in an arms-length transaction after proper marketing wherein the parties had each acted knowledgeably, prudently, and without undue influence 
(International Valuation Standards, 2005). Market value itself has subcategories such as foreclosure value, fair market value and distressed sale value.

2. Value-in-use: This is the net present value (NPV) of a cash flow that an asset is expected to generate for a specific owner under a specific use. Value-in-use is the value to one particular user and may be above or below the market value of a property.

3. Investment value: This is the value to one particular investor and is usually higher than the market value of a property due to the intangible aspects discussed above.

4. Insurable value: This is the value of real property covered by an insurance policy; and generally, this value does not include the site value.

5. Liquidation value: This may be analyzed as either as a forced liquidation or an orderly liquidation and is a commonly sought standard of value in bankruptcy proceedings. It assumes a seller who is compelled to sell after an exposure period, which is most likely to less than the market value in a normal timeframe.

There are three general groups of methodologies for determining the above values; and these are generally independent of each other. These methodologies are (1) the cost approach; (2) the sales comparison approach; and (3) the income approach. The first two use ex-post data, whilst the last approach uses ex-ante estimates. Appraisers generally choose from one or two of these approaches in undertaking their valuations, as best fits the situation. For example, appraisals of properties that are typically purchased by investors (e.g., skyscrapers, office buildings) may give greater weight to the income approach. Buyers interested in purchasing single-family residential property would rather compare price, and therefore the sales comparison approach would be more applicable. The cost approach to value is most useful in determining insurable value, and cost to construct a new structure or building. 


\section{The Real Estate Capability (REC) Valuation Approach}

Ratnatunga et al. (2004) and Ratnatunga and Ewing (2005) suggest that there is a strong and demonstrable link between what an organization spends in a particular period on an asset, and how such expenditure can increase (or if the spend is inadequate, decrease) the asset's value. Such a valuation approach is no different to the traditional revaluation of a noncurrent (fixed) asset, which will be dependent on the extent of money expended to increase or maintain its capability.

At this point, it is important to define and contrast different value components. An 'Asset' is what one has, much like a Ferrari motor car (tangible asset) or Michael Schumacher's remarkable driving skill (intangible asset). A 'Capability' is what can be achieved (or what one can do) when these asset categories are combined in a contextual situation, that is, winning a Formula 1 championship. A 'Capability Value' is the economic value of the capability (i.e. the current/future monetary value to Ferrari in winning major racing championships and thus selling more cars).

Ratnatunga et al. (2004) and Ratnatunga and Ewing (2005) calculate asset values via a single-period valuation process using Expense Leveraged Value Indices (ELVI) obtained by statistical means or by consensus. This paper extends their work by demonstrating that the ELVI approach is suitable for taking targeted actions to enhance real estate capability values. The following equation (developed from work originally done by Vidale \& Wolf, 1957) demonstrates the relationship of the ELVI to capability values:

\section{Equation 1:}

$$
\frac{d S}{d t}=r \cdot E \cdot\left(\frac{M-S}{M}\right)-\delta S
$$

The equation indicates that the change in the economic value ( $d S / d t)$ of a capability-enhancing asset at time ' $\mathrm{t}$ ' is a function of five factors:

$\mathrm{E}$ : the costs/expenses incurred to support the capability from purchase date. 
r: the value-increasing constant (ELVI No.1- defined as the value generated per expense dollar when $S=0$ ).

M: the maximum consensus value of the capability at the current date.

S: the value of the capability at time of purchase.

$\delta$ : the value-decay constant (ELVI No.2 - defined as the fraction of value lost per time unit when $\mathrm{E}=0$ ).

The equation states that the change (increase) in the capability value will be higher when $\mathrm{r}, \mathrm{E}$, and the untapped capability potential are higher, and the value-decay constant is lower. Ratnatunga et al. (2004) used this model to value military capabilities; and Ratnatunga and Ewing (2005) to value marketing communications (IMC) capabilities. We will use it to value a real estate capability at a point in time.

It stands to reason that the more logistical and financial support is invested in an asset (say a house property) the more capable it becomes; and if there was no expenditure incurred on it the less capable it becomes. The difficulty lies, however, in estimating the relationship between the expenditure and the resultant capability enhancement or diminution. As a hypothetical example, let us assume that a property was purchased at a price of 1,500,000 10 years ago. Since then, assume that the property owner has expended money (E) to date on the property for "enhancement" (e.g. an extension) and "maintenance" (e.g. re-painting) of \$160,000. Due to the economics of diminishing returns, however, this property, like all economic assets, would have a maximum sales capability potential, no matter how many financial and other resources are lavished on it. Let us assume that this maximum (appraiser's consensus-based) capability potential is $\$ 2,500,000$ at the current date.

Assume that the appraiser, based on its past experience, estimates the value-increasing constant of this property for each dollar of financial support given (r) to be 6 , and the value-decay constant $(\delta$ ) had this financial support been withdrawn to be .02 . The appraiser can use these variables and constants to calculate the capability value of the property using the equation presented earlier as follows: 


$$
\begin{aligned}
\left(\frac{\mathrm{d} S}{\mathrm{dT}}\right) & =6 \cdot 160,000 \cdot\left(\frac{2,500,000-1,500,000}{2,5000,000}\right)-0.02(1,500,000) \\
\left(\frac{\mathrm{dS}}{\mathrm{dT}}\right) & =6(0.4) \cdot 160,000-30,000=\$ 354,000
\end{aligned}
$$

Thus, based on these ELVI, by spending $\$ 160,000$ on capability support, the capability value has been leveraged up by a significant $\$ 354,000$ or a net- ELVI of 1.2125 . The total capability value of the property at that point in time would now be $\$ 1,500,000+\$ 354,000=$ $\$ 1,854,000$, which is what it should be put on the market at.

Note that if the owner in the preceding example had completed neglected the property and spent only $\$ 5,000$ on capability support, by applying the capability-enhancing asset equation the change in economic value (dS/dt) works out to be a negative $\$ 18,000$, or a net- ELVI of minus 4.60. The property would now be worth only $1,482,000$. Thus, all assets would have a range of net- ELVI, some greater than 1, some between 0 and 1 , and some negative. 1 So, the model is not biased only in the positive (capability enhancing) direction, nor are the resultant values linear to the amount of expenditure. That is, inputs to the model will not always produce a positive result, as a property not supported at the proper level may result in a weakened market position vis-à-vis other properties in that location, due to its (poor) external appearance or (poor) internal layout.

\footnotetext{
${ }^{1}$ Note also that as the negative net- ELVI values reduce capability asset values, this is conceptually very similar to the depreciation/amortisation of assets under traditional financial reporting, whilst the positive net- ELVI related values are similar to the revaluation of asset values under traditional financial reporting.
} 
Table 1. The Seven Components of Real Estate Strength

Real Estate Strength Variable

Location: Actions here mainly focus on long-term customer perceptions of real estate desirability. Often these actions are local community based with individuals contributing via taxes and rates.

Age/Style: Actions here mainly focus on either enhancing or disguising the period in which the property was originally constructed.

Presentation: Actions here mainly focus on presenting the property in its best possible light.

Layout: Actions here are to make the property have features that increase its desirability by the targeted market.

Trend: Actions here include real estate location image and changes in the pricequality-value relationships of the style and features of the property.

\section{Reason for Inclusion}

To achieve a high score, the real estate location must be a dominant force in its sector with a strong market demand. Factors such as closeness to CBD, Schools, Hospitals, Roads, Public Transport, Parks and Shopping increase this score. The size of the land is a key factor here.

To achieve a high score, the real estate location must portray a period style for which there is a strong demand. Factors such as paint colours, brickwork, tiles, carpets, fitouts, kitchen style etc., externally and internally, could enhance or diminish this score.

To achieve a high score, the real estate location must portray liveability. Factors such as surroundings, building strength, overall neatness, maintenance of property including the garden, ease of opening doors and windows, carpet durability; and the absence of leaks, mould, paint flaking, etc. could enhance this score.

To achieve a high score, the real estate layout must have contemporary features such as number and size of bedrooms, bathrooms and toilets, walk-in-robes, living and dining areas, garage sizes, balconies etc. Building extensions to incorporate more features could enhance this score, but overcapitalization could also diminish this score.

To achieve a high score, the trend is analysed in terms of its positioning; i.e. a property's ability to remain contemporary and hence retain profitability. Factors such as fashionability, lifestyle of target market, demographics, and family size trends are considered in the scoring. 
Marketing Support: Actions here include 'pull' advertising such as in print and electronic media and 'push' promotion via real estate agents. These actions affect all the other real estate capability variables. However, marketing treated as a separate variable as the effectiveness of marketing is integral to a property's ultimate capability value.

Protection: Actions here include the strength of title deeds, easements, planning and building permits, heritage listings, covenants etc. pertaining to the property.
In the short-term, the level of marketing support expenditures is an essential feature in the calculation of profitability. To achieve a high score, the integrated marketing communications (IMC) support provided must be in line with the location, style, layout, presentation and trend aspects of the property.

This factor is generally an opportunity to express doubts or concerns over a real estate's relative level of protection, e.g., challenges to the title deeds etc., rather than to appraise its absolute existence.

It would be a mistake to aim for global standards in value-enhancing (r) or value-decaying $(\delta)$ constants in property valuation because the factors that affect the strength of a property's capability is so diverse (see Table 1). Instead, the aim should be to develop measures tailored to particular suburbs, which could be adjusted to take into account a property's unique strengths. Where relevant, the already established 'real estate valuation approaches discussed earlier should be used and incorporated into the overall capability valuation.

\section{Enhancing Real Estate Capabilities}

The above example demonstrates how a value can be calculated at a point in time by considering the ex-post expenditure invested in a property. However, the interdependent nature of ex-ante actions that could be undertaken to enhance REC values make the application of the above univariate capability valuation model somewhat restrictive. Actions that increase REC values require an integrated approach. For the development of the REC valuation model to provide useful information for ex-ante resource allocation purposes, it needs to be extended in a multivariate manner to deal with complex REC factor inter-relationships. Taking a lead from the real estate valuation literature (see, Baum \& Mackmin, 1995; Brown \& Matysiak, 1999; Rees \& Hayward, 2000; Isaac, 2002; Pagourtzi, Assimakopoulos, Hatzichristos \&French, 2003; Kane, Linne \& Johnson, 
2004; Adair \& Hutchison, 2005; Maliene, Deveikis, Kirsten, \& Malys, 2010), seven strength factors that affect real estate values were recognized and presented as the preconditions (or antecedents) required for the inducement of current and future sales (which are the consequences) (see Table 1). These antecedents (or variables) act via an intermediate variable, Real Estate Capability (REC) (see Figure 1). 
Management Accounting Frontiers 4 (2021) 5-26

Figure 1. Antecedents and Consequences of Real Estate Capability

Antecedents

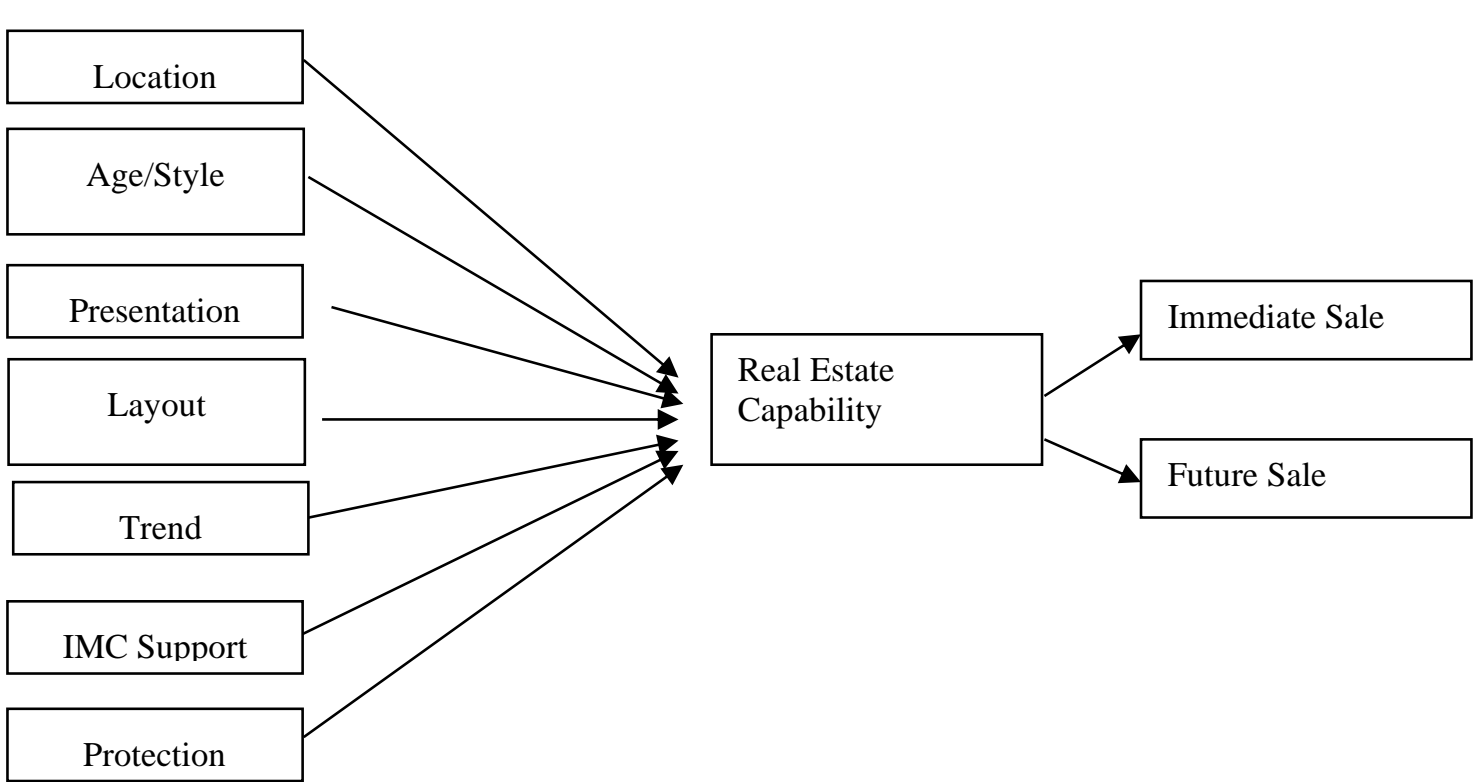


Based both on the preceding literature and conventional wisdom with regards to real estate valuation, it can be posited that the expenses targeted to enhance these seven strength factors can potentially have both an attitudinal effect in terms of real estate recognition and the perceived quality of the real estate, and a behavioral effect on sales. Thus, there needs to be integration of the many RE strengths that constitute the value enhancing efforts required to enhance real estate capability (REC) value, as follows:

\section{Equation 2:}

$$
\frac{d S}{d t}=\sum_{i}^{N}\left[r_{i} E_{i}\left(\frac{M_{i}-S_{i}}{M_{i}}\right) p_{i}-\delta_{i} S_{i}\right]
$$

The equation indicates that the change in the economic value $(d S / d t)$ of capability-enhancing activity at time ' $\mathrm{t}$ ' is a function of:

$\mathrm{E}_{\mathrm{i}}$ : The costs that should be incurred in supporting the capability of the ith Real Estate Strength (RES) variable over a defined period of time.

$\mathrm{r}_{\mathrm{i}}$ : The value-increasing ELVI constant of the ith real estate strength variable (defined as the value generated per expense dollar when $\mathrm{S}=$ $0)$.

M The maximum consensus value of the Real Estate Capability (REC) at end of value enhancement period.

S The current value of the REC (based on the Equation 1).

$\delta$ I The value-decay ELVI constant of the ith RES variable. (Defined as the fraction of value lost per time unit when $\mathrm{E}=0$ ).

$p_{i}$ The proportion of funds expended on the ith RES variable, where $\sum_{i}^{N} p_{i}=1$

N Total number of RES variables (see Figure 1). 
The extension of the univariate model to incorporate ex-ante investment in capability enhancing real estate strengths requires the derivation of the $p_{i}$ measure for each RES variable. This will initially have to be a consensus measure, until there is further development in experience in using the model. Note in the equation above, the value increasing ELVI constant $\left(r_{i}\right)$ is the only factor impacted by the proportion of funds $\left(p_{i}\right)$ invested in it. The value decaying ELVI constant $\left(\delta_{i}\right)$ is the diminution of the asset value if there is no further investment of funds in it. Thus, the range of values for $r_{i}$ and $\delta_{i}$ are very different. The value-increasing $r_{i}$ constant is very similar to (say) an advertising-sales response function, where each dollar invested in advertising could result in a sales dollar multiple of 4 to 20 times (or more). The only limitation to not spending limitless amounts on advertising (and getting limitless amounts of sales revenue) is first, that the $r_{i}$ constant only holds for a relevant range, and second, that there is a saturation level of sales based on the life cycle of the product. The same applied to the link between expenses incurred on RE strengths and RECs. In the above equation with the $M_{i}$ variable, defined as the maximum consensus value of a particular RE capability, captures this saturation level. The range of the value-decreasing $\delta_{i}$ is, on the other hand, very limited as a value of 1 in this variable indicates that all value will be lost (i.e. fully amortized within the period) if the support of that particular RES variable in that period does have any expenses incurred on it. A value more than 1 indicates that an asset that has no money spent on it will become a liability.

\section{A Hypothetical Example of the Use of the Model}

The starting point for the REC valuation is the current market value (S) based on Equation 1, and the maximum consensus value (M) that can be obtained at the end of the value enhancement period when the property will be ready for sale. The current methods of obtaining these values such as the (1) the cost approach; (2) the sales comparison approach; (3) the income approach or (4) a combination of such can be used to bring a degree of triangulation and reality into these variable. As we are discussing capabilities as opposed to tangible asset values, some consensus would need to be obtained as to if these values also incorporate the intangible aspects of the asset. Let us assume that the current values is $\$ 750,000(\mathrm{~S})$; and the maximum consensus value possible at the end of the value enhancement period $\$ 1,500,000(\mathrm{M})$. 
Next, there needs to be an estimation by the appraiser (or by consensus) of the contribution of each of the RES Variable to the RE Capability enhancement of the asset. These are weights (in terms of importance) applied to each of the real estate strength (Table 1) components (or antecedents, see also Figure 1), required to maintain or increase the property's REC Value. Table 2 provides hypothetical consensus estimates used to value each RES variable's current capability $(\mathrm{Si})$ and maximum capability $(\mathrm{Mi})$ at the end of the value enhancement period.

Table 2. Contribution of Real Estate Strength Variables to REC

\begin{tabular}{llll}
$\begin{array}{l}\text { Real Estate } \\
\text { Strength Variable }\end{array}$ & Weight & $\begin{array}{l}\text { Current Real } \\
\text { Estate Value }\end{array}$ & $\begin{array}{l}\text { Maximum Real } \\
\text { Estate Value }\end{array}$ \\
\hline Location & $55 \%$ & $\$ 412,500$ & $\$ 825,000$ \\
Age/Style & $5 \%$ & $\$ 37,500$ & $\$ 75,000$ \\
Presentation & $10 \%$ & $\$ 75,000$ & $\$ 150,000$ \\
Layout & $18 \%$ & $\$ 135,000$ & $\$ 270,000$ \\
Trend & $5 \%$ & $\$ 37,500$ & $\$ 75,000$ \\
IMC Support & $3 \%$ & $\$ 22,500$ & $\$ 45,000$ \\
Protection & $4 \%$ & $\$ 30,000$ & $\$ 60,000$ \\
\hline
\end{tabular}

Assume that $\$ 50,000$ (E) is expected to be spent by the owners on enhancing the REC during the value enhancement period, the appraiser can request the owners (or advise them) to provide an initial iteration of the expected proportion of funds they would be expending on each RES variable (pi) as presented in Table 3 . 
Table 3. Percentage Estimated Spend on each Real Estate Strength

\begin{tabular}{|c|c|c|c|c|c|c|}
\hline \multirow[t]{2}{*}{$\begin{array}{l}\text { Real Estate } \\
\text { Strength Variable }\end{array}$} & \multicolumn{2}{|c|}{ Iteration 1} & \multicolumn{2}{|c|}{$\begin{array}{l}\text { Sensitivity } \\
\text { Iteration } 2\end{array}$} & \multicolumn{2}{|c|}{$\begin{array}{l}\text { Sensitivity } \\
\text { Iteration } 3\end{array}$} \\
\hline & Est. & Act. & Est. & Act. & Est. & Act. \\
\hline Location & $10 \%$ & & $11 \%$ & & $12 \%$ & \\
\hline Age/Style & $15 \%$ & & $20 \%$ & & $10 \%$ & \\
\hline Presentation & $15 \%$ & & $15 \%$ & & $10 \%$ & \\
\hline Layout & $30 \%$ & & $40 \%$ & & $40 \%$ & \\
\hline Trend & $9 \%$ & & $5 \%$ & & $5 \%$ & \\
\hline IMC Support & $16 \%$ & & $5 \%$ & & $18 \%$ & \\
\hline \multirow[t]{2}{*}{ Protection } & $5 \%$ & & $4 \%$ & & $5 \%$ & \\
\hline & $100 \%$ & & $100 \%$ & & $100 \%$ & \\
\hline
\end{tabular}

The most difficult part of empirically validating the valuation model will be obtaining data for the various ELVI constants, both value-increasing $\left(r_{i}\right)$ and value decreasing $\left(\delta_{i}\right)$, for each of the RES variables in terms of their contribution to Real Estate Capability Value (Table 4). This is mainly due to the different 'value ranges' required for the $r_{i}$ and $\delta_{i}$ constants. Furthermore, as the multivariate model equation was being used (Equation 2 ), the non-linear functions will be difficult to work with in obtaining consensus values. However, repeated trials of different ELVI values using an Excel model should provide the appraisers and Owners with a reasonable understanding of the dynamics of the equation. Table 4 gives hypothetical consensus values. [Note that the values in the last column of Table 4 are derived using the multivariate Equation 2 for each of the RES variables].

One can see that as the total spend on value enhancing activities is budgeted at $\$ 50,000$, the RES capability incremental value component of the REC Value based on the proportion of funds expended on each RES variable is approximately a positive $\$ 116,925$. This means that the $\$ 50,000$ to be spent is more than adequate to not only maintain, but also enhance 
the RE capability value from $\$ 750,000$ to $\$ 866,925$ over the value enhancement period.

Table 4. Real Estate Capability Growth or Decline

\begin{tabular}{lllll}
$\begin{array}{l}\text { Real Estate } \\
\text { Strength Variable }\end{array}$ & $\begin{array}{l}\text { Value- } \\
\text { increasing } \\
\text { ELVIM } \\
\text { constant }\end{array}$ & $\begin{array}{l}\text { Value- } \\
\text { decaying } \\
\text { ELVI } \\
\text { constant }\end{array}$ & $\begin{array}{l}\text { Percentage } \\
\text { of Costs } \\
\text { Expended }\end{array}$ & $\begin{array}{l}\text { Real Estate } \\
\text { Strength Variable } \\
\text { Contribution to } \\
\text { REC incremental }\end{array}$ \\
\hline Location & 5.8 & 0.08 & $10 \%$ & $\$(18,500)$ \\
Age/Style & 9.5 & 0.6 & $15 \%$ & $\$ 13,125$ \\
Presentation & 9.5 & 0.4 & $15 \%$ & $\$ 5,625$ \\
Layout & 12.2 & 0.08 & $30 \%$ & $\$ 80,700$ \\
Trend & 0.9 & 0.05 & $9 \%$ & $\$ 150$ \\
IMC Support & 10 & 0.2 & $16 \%$ & $\$ 35,500$ \\
Protection & 0.5 & 0.01 & $5 \%$ & $\$ 325$ \\
\hline Real Estate Capability Incremental Value & & $\$ 116.925$ \\
\hline
\end{tabular}

\section{Sensitivity Analyses of Alternative Real Estate Investment Scenarios}

Suppose due to budgetary constraints, the owner wishes to only maintain the same RE capability (and hence the same sales potential as current), rather than the increase incremental capability currently achieved due to a high spend level of $\$ 50,000$. Then (using the goal-seek function in Excel) the model equation will indicate that approximately $\$ 23,500$ (i.e. $\$ 23,414$ ) will need to be expended, to maintain its RE capability at its initial value. This would be the zero-based level of expenditure on RE strength enhancing activities for RE capability maintenance (i.e. nil REC increase). Cutting costs below this would result in a loss of capability (see Table 5). This concept is no different to the expenses a company would 
need to spend on repairs and preventive maintenance of its tangible assets (e.g. delivery vehicles). Just to keep the vehicles running at its current level of economic capability, a certain level of expenses would need to be incurred.

Table 5. Real Estate Capability Maintenance

\begin{tabular}{lllll}
$\begin{array}{l}\text { Real Estate } \\
\text { Strength Variable }\end{array}$ & $\begin{array}{l}\text { Value- } \\
\text { increasing } \\
\text { ELVIM } \\
\text { constant }\end{array}$ & $\begin{array}{l}\text { Value- } \\
\text { decaying } \\
\text { ELVI } \\
\text { constant }\end{array}$ & $\begin{array}{l}\text { Percentage } \\
\text { of Costs } \\
\text { Expended }\end{array}$ & $\begin{array}{l}\text { Real Estate } \\
\text { Strength Variable } \\
\text { Contribution to } \\
\text { REC incremental }\end{array}$ \\
\hline Location & 5.8 & 0.08 & $10 \%$ & $\$(26,210)$ \\
Age/Style & 9.5 & 0.6 & $15 \%$ & $\$(5,817)$ \\
Presentation & 9.5 & 0.4 & $15 \%$ & $\$(13,317)$ \\
Layout & 12.2 & 0.08 & $30 \%$ & $\$ 32,048$ \\
Trend & 0.9 & 0.05 & $9 \%$ & $\$(927)$ \\
IMC Support & 10 & 0.2 & $16 \%$ & $\$ 14,231$ \\
Protection & 0.5 & 0.01 & $5 \%$ & $\$(7)$ \\
\hline Real Estate Capability Incremental Value & & $\$ \mathbf{\$ 0}$ \\
Total Estimated Spend on RE Strength Enhancing Activities & $\mathbf{\$ 2 3 , 4 1 4}$ \\
\hline
\end{tabular}

Note that due to the non-linear function in the equation used, a reduction in budget spend of only $\$ 26,586(\$ 50,000-\$ 23,414)$ results in the incremental RE capability value decreasing significantly, from $\$ 116,925$ to zero. As one can see, therefore, such a model will be extremely useful in helping resolve recurring issues pertaining to targeted spending on real estate strengths. One can see from Table 5 that even this zero-based expenditure level, whilst maintaining the capability value overall, is however inadequate to maintain some individual RES component values (e.g. Location, Age/Style, Presentation and Trend now all show negative 
capability values; whilst in Table 4 only Location was negative). Thus, the goal seek function can be utilized again to ascertain the minimum expenditure required to maintain (say) the level of Presentation.

Table 6. Real Estate Capability Growth (Iteration 2)

\begin{tabular}{lllll}
$\begin{array}{l}\text { Real Estate } \\
\text { Strength Variable }\end{array}$ & $\begin{array}{l}\text { Value- } \\
\text { increasing } \\
\text { ELVI } \\
\text { constant }\end{array}$ & $\begin{array}{l}\text { Value- } \\
\text { decaying } \\
\text { ELVI } \\
\text { constant }\end{array}$ & $\begin{array}{l}\text { Percentage } \\
\text { of Costs } \\
\text { Expended }\end{array}$ & $\begin{array}{l}\text { Real Estate } \\
\text { Strength Variable } \\
\text { Contribution to } \\
\text { REC incremental }\end{array}$ \\
\hline Location & 5.8 & 0.08 & $11 \%$ & $\$(17,050)$ \\
Age/Style & 9.5 & 0.6 & $20 \%$ & $\$ 25,000$ \\
Presentation & 9.5 & 0.4 & $15 \%$ & $\$ 5,625$ \\
Layout & 12.2 & 0.08 & $40 \%$ & $\$ 111,200$ \\
Trend & 0.9 & 0.05 & $5 \%$ & $\$(750)$ \\
IMC Support & 10 & 0.2 & $5 \%$ & $\$ 8,000$ \\
Protection & 0.5 & 0.01 & $4 \%$ & $\$ 200$ \\
\hline Real Estate Capability Incremental Value & & $\mathbf{\$ 1 3 2 , 2 2 5}$ \\
Total Estimated Spend on RE Strength Enhancing Activities & $\mathbf{\$ 5 0 , 0 0 0}$
\end{tabular}

The model can also increase REC values by expending different proportions of funds on the individual BS variables. Using the iteration 2 column from Table 3, and keeping the total spend at the iteration 1 level of (the original) $\$ 50,000$, the incremental REC value increases to $\$ 132,225$ (see Table 6). When comparing this to Table 4 (where REC value increased by $\$ 116,925)$, an additional RE capability value increase of $\$ 15,300$ can be estimated. Thus, the owner has got "more bang for the buck" by spending the same amount of money, but simply changing its strategic focus on the RES variables that produce the most RE capability enhancement. 


\section{Conclusions}

The REC valuation model presented in this paper is a pragmatic approach to both valuing current real estate capabilities and enhancing the values of tangible and intangible capabilities of a property in the future by utilizing Expense Leveraged Value Indexes (ELVI). Most real estate valuation approaches are largely based on ex-post historical values or the net present value of ex-ante income projections at a point in time. No consideration is given to how values are (and can be) enhanced by targeted expenditure on certain strengths of a property. The present paper provides a univariate capability model to value a property at a point in time based on past expenditure investments on it; and a multivariate model that incorporates specified real estate strength variables (as antecedents) for RE capability enhancement. It also provides an approach for estimating expenditures required to either enhance or maintain such a value. The models in this paper are a work-in-progress rather than a fait accompli. However, there is hopefully an underlying theoretical and methodological rigor that will provide a basis for property-specific refinement and application. Moreover, the model provides a structure for owners to calculate the value of their real estate and invest successfully in the appropriate elements of their property. By applying a method that integrates the intangible and tangible components, both sellers and buyers have a more realistic tool to apply to increase the valuation of the real estate they hope to sell or buy. Additionally, the incorporation of multivariate analysis provides a more robust model for owners to calculate, and target, their real estate expenditures. This functionality of the model also allows appraisers to present clearer, and statistically supported arguments to their clients when recommending real estate expenditures that enhance values. 


\section{References}

Adair, A. and Hutchison, N., (2005). "The Reporting of Risk in Real Estate Appraisal Property Risk Scoring", Journal of Property Investment \& Finance, Vol. 23 No. 3, pp. 254-268.

Baum, A. and Mackmin, D., (1995), The Income Approach to Property Valuation, Routledge, London.

Breech, C., (1997), "Introduction to Investment property", in R. Westwood (ed.), Valuation Principles and Practice, Australian Property Institute, Deakin, pp. 85-103.

Brown, G. R. and Matysiak, G. A., (1999), Real Estate Investment: A Capital Market Approach. Financial Times, London.

International Valuation Standards, (2005), IVS 1 Market Value Basis of Valuation/Scope, International Valuation Standards Council, London, pp. 94-106.

Isaac, D., (2002), Property Valuation Principles, Palgrave, London.

Kane, S., Linne, M. and Johnson, J., (2004), Practical Applications in Appraisal Valuation Modeling, Appraisal Institute, Chicago.

Maliene, V., Deveikis, S., Kirsten, L. and Malys, N., (2010), "Commercial Leisure Property Valuation: A Comparison of the Case Studies in UK and Lithuania", International Journal of Strategic Property Management, Vol. 14 No. 1, pp. 35-48.

Pagourtzi, E., Assimakopoulos, V., Hatzichristos, T. and French, N., (2003), "Real Estate Appraisal: A Review of Valuation Methods", Journal of Property Investment \& Finance, Vol. 21 No. 4, pp. 383-401.

Ratnatunga J. Gray N. and Balachandran K. R., (2004), "CEVITA ${ }^{\mathrm{TM}}$ : The Valuation and Reporting of Strategic Capabilities", Management Accounting Research, Vol. 15 No. 1, pp. 77-105.

Ratnatunga J. and Ewing M., (2005), "The Brand Capability Value of Integrated Marketing Communication", Journal of Advertising, Vol. 34 No. 4, pp. 25-40. 
Rees, W. H. and Hayward, R. E. H., (2000), Valuation: Principles into Practice, Estates Gazette, London.

Simons, R., (2007), When Bad Things Happen to Good Property, Environmental Law Institute, Washington.

Vidale M. D. and Wolfe H. B., (1957), "An Operations Research Study of Sales Response to Advertising", Operation Research, Vol. 5 No. 3, pp. 370-381. 
Management Accounting Frontiers 4 (2021) 5-26 